\title{
Characteristics of Hybrid Modified Percutaneous Dilatational Tracheostomy in Patients With COVID-19: A Single Institutional Experience Over 1 Year
}

\author{
Min Ji Kim ${ }^{1}$ D, Yeon Soo Choi ${ }^{1}$, Jung Soo Kim ${ }^{2}$, Jin-Soo Lee ${ }^{3}$, and Ji Won Kim ${ }^{1} \mathbb{D}$ \\ ${ }^{I}$ Department of Otorhinolaryngology-Head and Neck Surgery, Inha University College of Medicine, Incheon; and \\ ${ }^{2}$ Division of Pulmonary and Critical Care Medicine, Department of Internal Medicine, Inha University Hospital, \\ Inha University School of Medicine, Incheon; and \\ ${ }^{3}$ Division of Infectious Diseases, Department of Internal Medicine, Inha University School of Medicine, Incheon, Korea \\ COVID-19 환자의 변형된 경피적 기관절개술의 특성 분석: 1 년간의 단일 기관 경험 \\ 김민지 $^{1} \cdot$ 최연수 ${ }^{1}$ 김정수 ${ }^{2} \cdot$ 이진수 ${ }^{3} \cdot$ 김지원 $^{1}$ \\ 인하대학교 의과대학 ${ }^{1}$ 이비인후과학교실, ${ }^{2}$ 내과학교실 호흡기내과, ${ }^{3}$ 내과학교실 감염내과
}

\author{
Received May 3, 2021 \\ Revised June 26, 2021 \\ Accepted July 13, 2021 \\ Address for correspondence \\ Ji Won Kim, MD, PhD \\ Department of Otorhinolaryngology- \\ Head and Neck Surgery, \\ Inha University College of Medicine, \\ 27 Inhang-ro, Jung-gu, \\ Incheon 22332, Korea \\ Tel $+82-32-890-3028$ \\ Fax $+82-32-890-3580$ \\ E-mail hopefuljw@gmail.com
}

Background and Objectives Coronavirus disease 2019 (COVID-19) is a worldwide pandemic, and some patients require mechanical ventilation and tracheostomy. Owing to the risks of aerosol spreading to health care workers, the protocols and guidelines related to the novel timing and technique for tracheostomy are rapidly changing. We investigated the characteristics of tracheostomy with patients with COVID-19 over a year.

Subjects and Method We measured the mean time from intubation to the tracheostomy, survival rate, the incidence of infection to medical staff, and operation time, complications for tracheostomy, and the time of decannulation. All patients underwent a novel percutaneous tracheostomy without bronchoscope (hybrid modified percutaneous dilatational tracheostomy, hybrid MPDT) in the negative pressure intensive care unit.

Results Of the 448 patients with COVID-19 patients, 34 required invasive mechanical ventilation at a tertiary hospital from February 2020 to April 2021. Of those, 15 patients underwent tracheostomy. Of the tracheostomy patients, survival rate was $93.33 \%$. The mean time from intubation to the tracheostomy was $18.27 \pm 14.74$ days (range, $8-36$ days). The incidence of infection to medical staff was zero percent whereas racheostomy-related bleeding was the most common complication ( 2 patients). Operation time for hybrid MPDT was $5.45 \pm 1.12 \mathrm{~min}$. Conclusion The optimal timing of tracheostomy procedure for COVID-19 patients is still unknown, but it is believed that the treatment of COVID-19 can be achieved better if the hybrid MPDT is used at the right time. Korean J Otorhinolaryngol-Head Neck Surg 2022;65(4):220-5 Keywords COVID-19; SARS-CoV-2; Tracheostomy.

\section{서 론}

중증 급성 호흡기 증후군 코로나 바이러스-2 (SARS$\mathrm{CoV}-2$ )로 인한 코로나바이러스감염증-19 (coronavirus disease 2019, COVID-19)는 2019년 12월 중국 우한에서 시
작되어 불과 3개월 만에 전 세계적으로 대유행(pandemic) 단 계로 발전했다. ${ }^{1)}$ COVID-19 환자의 80\%는 경증의 질병 경과 를 보이나, 5\%-15\%의 환자에서 빠른 속도로 악화되는 폐렴 과 이로 인한 급성호흡곤란증후군(acute respiratory distress syndrome)과 저혈압, 빈맥, 심부전 증상을 보이는 심근염 등

This is an Open Access article distributed under the terms of the Creative Commons Attribution Non-Commercial License (https://creativecommons.org/licenses/by-nc/4.0) which permits unrestricted non-commercial use, distribution, and reproduction in any medium, provided the original work is properly cited. 
중증의 경과를 나타낸다. 이들은 기관 내 삽관, 체외막산소공 급 치료 등의 중환자실 치료를 받게 되며, 이 중 일부의 환자 는 기관절개술을 요하게 된다. ${ }^{2}$ 에어로졸 생성 및 전염 가능 성이 있는 기관절개술을 시행함에 있어서 의료진 감염의 위 험성 및 환자에게 적절한 호흡기 치료 방법 필요성 등을 고려 하여 현재 기관절개술의 시기 및 방법에 대해 여러 가이드라 인이 나오고 있는 실정이나-11) 아직 정립된 의견은 없다. 2020 년 Vargas 등른 은 COVID-19 에어로졸 전염을 낮추기 위해 변형된 경피적 확장 기관절개술 술기를 발표하였는데, 기관 내 삽관 튜브를 기관용골(carina) 상방까지 더 밀어 넣고 풍 선을 부풀린 상태에서, 기관내시경을 기관 내 삽관 튜브 외측 으로 기관 내 위치하게 하여 기관내시경을 보며 경피적 확장 기관절개술을 시행하는 방식이나, 좁은 공간에 좋은 시야를 확보하기 어렵고 기관내시경을 사용하는 인력이 감염 환경에 노출되는 단점이 있다.

저자들은 COVID-19 중증응급진료센터로 지정된 본원에 서 치료받은 COVID-19 환자 중 좁은 절개 범위로 에어로졸 의 형성을 줄여 의료진 감염위험을 낮추고 유도 철심을 통해 안전하고 정확하게 기관 절개용 튜브를 삽입할 수 있는 새로 운 방식의 하이브리드 변형 경피적 확장 기관절개술(hybrid modified percutaneous dilatational tracheostomy, hybrid $\mathrm{MPDT})$ 을 시행 받은 중증 환자들의 특성 및 이들에 대한 치 료에 대해 고찰해 보고자 한다.

\section{대상 및 방법}

본 연구는 2020년 2월부터 2021년 4월까지 COVID-19감 염으로 중환자 치료 중 기관절개술을 시행한 환자의 의무 기 록과 수술 후의 경부 사진을 후향적으로 검토하여 임상 양상 을 분석하였다. 시행한 기관절개술의 방법 등을 조사하였고, 본 연구는 인하대병원의 기관윤리심사위원회의 승인을 받아 진행되었다(No. 2021-05-008).

\section{기관절개술 시 보호장구 착용}

모든 기관절개술은 주변에 비해 $-2.5 \mathrm{~Pa}$ 의 압력을 유지하 는 음압 격리 중환자실에서 진행되었다. 인력은 집도의(이비인 후과 전문의), 집도 보조의(이비인후과 전공의 2-3년차), 간호 사 1 명으로 총 3 명으로 진행하였다. 참여하는 모든 의료진은 레벨D 방호복을 입은 후 허리에 차는 전동식 호흡장치(powered air-purifying respirator, PAPR)를 착용하며, 집도의는 머리 전체를 덮는 후드 위에 헤드라이트를 장착 후 기관절개 술을 시행하였다(Fig. 1).

\section{결 과}

COVID-19 치료 환자 중 기관절개술의 빈도

2020년 2월부터 2021년 4월까지 인하대병원에서 COVID-19 감염으로 치료를 받은 448명 중 기계환기치료를 위해 기관 내 삽관을 한 환자는 34명(7.6\%)이었다. 그 중 체외막산 소공급 치료를 한 환자는 12 명(2.7\%)이며 이 중 3명의 환자가 사망하였고, 기계환기치료만 치료했던 22명(4.9\%)의 환자 중 7명의 환자가 사망하였다. 따라서 원내 COVID-19 감염으로 치료를 받은 환자 중 10 명이 사망하여 사망률은 $2.2 \%$ 로 나 타났다. 기관 내 삽관을 한 환자 34 명 중 15명(44.1\%)의 환자 가 이비인후과에서 기관절개술을 시행 받았으며, 모든 시술 은 1 인의 이비인후과 전문의가 집도하였다.

\section{기관절개술을 시행 받은 환자의 특성}

기관절개술을 시행 받은 COVID-19 환자 총 15 명의 평균 연령은 69.8 \pm 15.4 세(54-81세)였고, 남성 13명(86.7\%), 여성 2명 (13.3\%)이었다. 현재 중환자실 치료 기간은 평균 $31.2 \pm 33.4$ 일 (15-77일)이며, 총 15 명의 환자 중 8 명(53.3\%)의 환자가 체외 막산소공급 치료를 받았고 7명(46.7\%)의 환자가 기계환기치 료를 받았으며, 1 명이 사망하여 사망률은 $6.7 \%$ 로 나타났다.

기관절개술의 시기, 방법 및 의료진 감염 빈도, 합병증

기관절개술은 기관 삽관 후 평균 18.27 \pm 14.74 일(8-36일) 후 시행되었으며, 시술 당시 모두 COVID-19 바이러스 양성 상 태였다. 모든 환자는 기관절개 후 감염원의 전파 경로 및 시 간을 최소화하기 위해 관혈적 기관절개술(surgical tracheostomy)과 경피적 확장 기관절개술(percutaneous dilatational tracheostomy, PDT)의 방법을 혼합하여 하이브리드 변형 경 피적 확장 기관절개술(hybrid MPDT)을 시행 받았다. Hybrid MPDT는 기관 노출 시까지 관혈적 기관절개술 방식으로 진 행하다가, 기관절개 후부터 Ciaglia Blue Rhino ${ }^{\circledR} \mathrm{PDT}$ kit (Cook Critical Care, Bloomington, IN, USA)를 사용하여 경피적 확장 기관절개술의 방식을 일부 변형하는 술식을 말 한다. Hybrid MPDT는 우선 관혈적 기관절개술처럼 경부에 최소 절개로 $1 \mathrm{~cm}$ 이하의 수평 피부 절개를 가한 후, 중앙에 서 근막을 수직 절개하여 기관을 노출시킨 후 1-2개의 기관 연골을 노출시킨다(Fig. 2). 이후에는 변형된 경피적 확장 기 관 절개술식으로 진행하는데 이를 자세히 기술하면, cold knife를 이용하여 기관 연골 절제 없이 $5 \mathrm{~mm}$ 길이로 연골막 절개를 내고(Fig. 3), 모스키토 겸자로 절개된 기관창을 약간 벌려, 안쪽으로 보이는 기관 내 삽관 튜브(endotracheal tube) 의 위치를 확인한다. 굴곡형 후두경 또는 기관 내시경 도움 

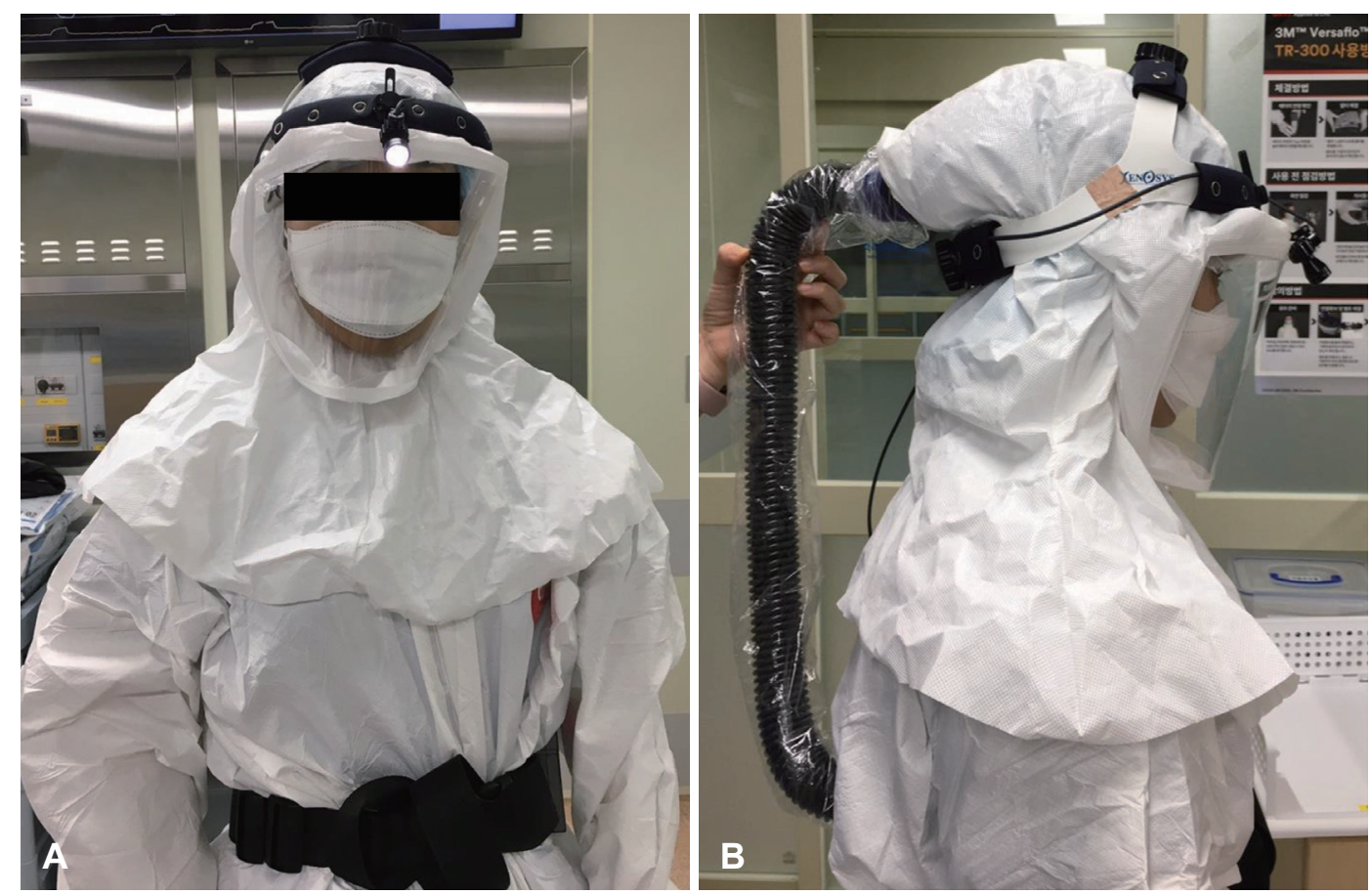

Fig. 1. The level $D$ protective suit and PAPR. Surgeon can wear a headlight on the hood before connecting PAPR blower tubing unit and hood. A: Front view. B: Lateral view. PAPR, powered air-purifying respirator.

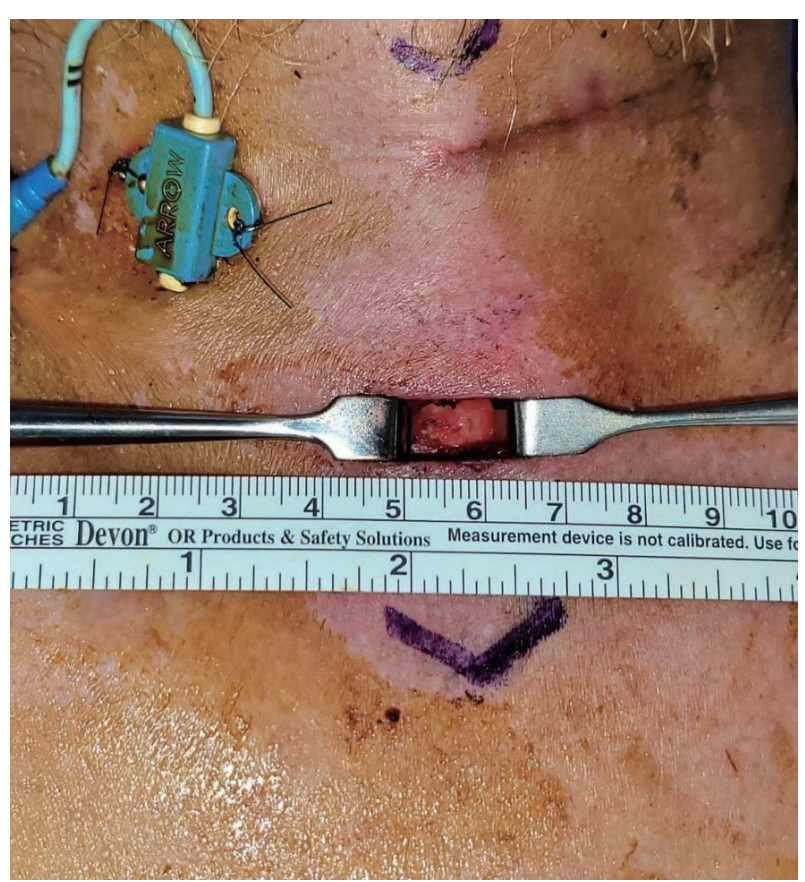

Fig. 2. The $1 \mathrm{~cm}$ length horizontal skin incision was made below one finger from the cricoid cartilage. The minimized dissection was performed until the trachea is exposed, and then about $1.5 \mathrm{~cm}$ sized surgical view is secured by retraction with Senn retractor.

없이, 기관 내 삽관 튜브의 팁 위치를 기관창을 통해 육안적 으로 확인하며, 서서히 기관 내 삽관 튜브를 빼내어 그 끝이 기관창 안쪽으로 보이지 않을 때(기관 내 삽관 튜브의 팁을 기관 절개창 직상방에 둔 상태에서) 튜브의 풍선을 부풀려 위
치를 고정한다. $18 \mathrm{G}$ 바늘이 달린 주사기를 이용한 기관 천자 과정을 생략하고, 이미 만들어놓은 기관 절개창에 확장기 (gradual dilator) (Fig. 4A)를 삽입 후, 확장기를 따라 유도 철심(Fig. 4B)을 삽입 후 유도 철심은 남긴 후 확장기를 제거 한다. 유도 철심을 따라 여러 크기의 확장기 중 가장 큰 사이 즈 $36 \mathrm{Fr}$ (Fig. 4C) 1개만을 사용하여 기관절개창을 확장 후 유도 철심을 따라 기관 절개 튜브(Fig. 4D)를 삽입하고 유도 철심을 제거한다. 평균 수술시간은 $5.45 \pm 1.12$ 분이었으며 시 술 이후 의료진은 별도의 격리를 시행하지 않았고, 의료진 감 염은 없었다(의료진 감염률: $0 \%$. 시술 후 합병증은 체외막 산소공급 치료를 위해 연속적 헤파린 정주를 하던 환자 2예 에서 각각 피하 연부조직, 피대근에서 발생한 출혈이 있었고, 기흥, 피하기종 등 기타 합병증은 발생하지 않았다.

기관절개용 튜브 종류 및 튜브의 교환 시기 및 방법

기관절개용 튜브는 모두 단일관으로 커프와 suction aid로 구성 된 튜브를 사용하였다. 기관절개용 튜브의 사이즈는 \#7.5 13명(86.7\%), \#7.0 2명(13.3\%)이었으며, 기관절개술 이후 발관 위험을 막기 위해 스트랩 고정 외에 튜브 양측에 나일론 을 이용하여 피부와 고정을 시행하였고, 이는 첫 기관 절개관 교환 후 함께 제거하였다. 기관절개관의 첫 교환 시기는 평균 $8.07 \pm 2.67$ 일 후 이비인후과 전공의에 의해 시행되었으며, 교 환 시기에도 모든 환자에서 COVID-19 양성이었으므로 레 벨D 방호복에 PAPR을 착용하고 기관절개용 튜브를 교환하 

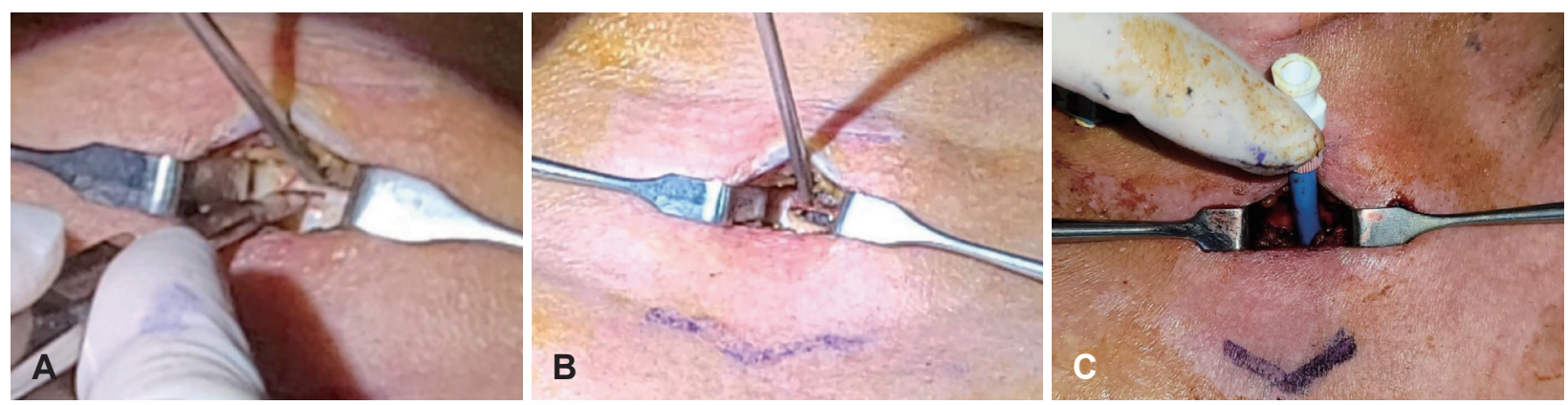

Fig. 3. Formation of small tracheal window to minimize aerosol release. A: Incision on tracheal membrane by cold knife. B: The hole of tracheal membrane following the bleeding control by a bipolar cauterizer. C: Insertion of gradual dilator through the hole of tracheal membrane.

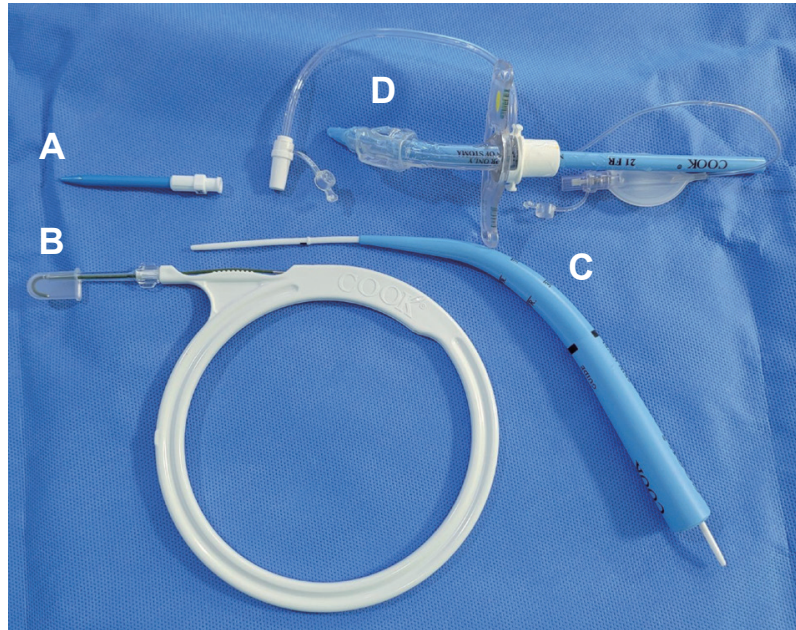

Fig. 4. Modified PDT needs selective four instruments in PDT kit (Ciaglia Blue Rhino ${ }^{\circledR}$; Cook Critical Care). A: Gradual dilator. B: Guide wire. C: $36 \mathrm{Fr}$ dilator. D: $21 \mathrm{Fr}$ dilator-inserted cuffed tracheostomy tube. PDT, percutaneous dilatational tracheostomy.

였다. 이후 주기적 기관절개용 튜브 교환은 해당 과에서 시행 하였다.

\section{기관절개용 튜브 제거}

기관절개술 후 튜브를 제거한 환자는 총 9명(60\%)으로 제 거까지의 평균 기간은 $49.0 \pm 39.2$ 일이었으며, 기관 절개공이

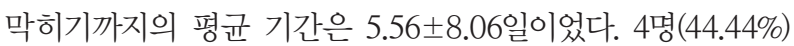
의 환자에서는 5 일부터 37 일까지 모두 40일 이내에 몽고메 리 테이핑 또는 듀오덤 드레싱으로 자발적으로 막혔고, 5명 (55.56\%)의 환자에서는 자발적으로 막히지 않아 국소마취하 기관피부누공(tracheocutaneous fistula)을 막는 수술을 시 행하였다(Table 1).

\section{고 찰}

기관절개술은 중환자에서 기계 호흡, 객담 배출, 지속적인 호흡기 유지를 위해서 시행한다. ${ }^{13)}$ COVID-19 환자의 기관절
Table 1. Characteristics of hybrid modified percutaneous dilatational tracheostomy in patients with COVID-19 $(n=15)$

\begin{tabular}{|c|c|}
\hline & Value \\
\hline Age (years) & $69.8 \pm 15.4(54-81)$ \\
\hline \multicolumn{2}{|l|}{ Sex } \\
\hline Male & $13(86.7)$ \\
\hline Female & $2(13.3)$ \\
\hline Survival & $14(93.3)$ \\
\hline ECMO apply & $8(53.3)$ \\
\hline
\end{tabular}

Days from intubation to tracheostomy

Number of COVID-19 positivity at

$18.3 \pm 14.7(8-36)$

tracheostomy

Number of COVID-19 transmission in

$15(100)$

medical staff

Tracheostomy technique

Hybrid MPDT

Time of operation ( $\mathrm{min}$ )

$5.45 \pm 1.12$

Tracheostomy tube size

$\# 7.0$

\#7.5

$13(86.7)$

Complications

Bleeding

Emphysema

$0(0)$

Pneumothorax

$0(0)$

Etc

$0(0)$

Time from tracheostomy to cannula

$8.07 \pm 2.67$

change (days)

Time from tracheostomy to decannulation

$49.0 \pm 39.2$

(days)

Data are presented as the $\mathrm{n}(\%)$ or mean \pm standard deviation (range). ECMO, extracorporeal membrane oxygenation; COVID-19, coronavirus disease 2019; MPDT, modified percutaneous dilatational tracheostomy

개술을 시행하는 적절한 시기와 시행 방법에 대해 각 나라마 다 다양한 권고안을 제시하고 있다. ${ }^{3-11)}$ 대부분의 가이드라인 에서는 COVID-19의 감염력은 환자가 증상을 나타낼 때 가 장 높으며 평균 18-20일간 바이러스의 전파가 일어나므로, 의 료진의 감염 위험성을 고려하여, 가능하면 시술 시기를 기관 
삽관일로부터 21일 이후로 시행하기를 권고하고 있으며, ${ }^{8)}$ 한 보고에 의하면 COVID-19 증상 발현부터 사망까지 기한이 평균 11 일이므로 조기 기관절개술보다는 최소 14 일에서 21 일 이후 생존할 수 있는 가능성이 있는 환자 군에게 선택적으로 시행하는 것이 기관절개술의 효과를 극대화할 수 있고, 동시 에 의료진의 감염 안전성을 어느 정도 보장할 수 있기에 1628 일 이후에 시행하기를 권고하고 있다.,8,14) 하지만 실제적으 로 기관삽관에서 기관절개술까지의 평균 기간이 약 10-12일 전후인 경우가 많이 보고되었고, ${ }^{15-17)}$ 본 기관에서는 기관삽관 에서 기관절개술까지 기간이 평균 $18.27 \pm 14.74$ 일(range, 836 일)로서 가이드라인인 21일에 비해서는 빠르지만, 다른 기 관들의 실제적인 보고들에 비해서는 다소 늦게 시행하는 경 향성을 보였다. 기관절개술을 시행 받은 환자들의 사망률이 $6.6 \%$ 로 다른 연구들에 비해 낮고, 30일 이상 생존율이 $93.3 \%$ 로 이전 연구들의 약 $68 \%$ 에 비해 높음을 고려하였을 때, ${ }^{18)}$ 본 기관에서는 어느 정도 생존할 수 있는 가능성이 있는 환 자군에게 선택적으로 기관절개술을 시행하였던 것으로 사료 된다. 또한, 많은 가이드라인이 COVID-19 검사가 음성일 때 까지 가능하면 기관절개술을 미루기를 권고하였는데 ${ }^{3)}$ 장기간 의 기관 내 삽관 유지로 인한 기관 협착 및 합병증으로 인한 우려도 있으므로 ${ }^{19}$ 적절한 시기에 기관절개술을 시행하는 것 이 중요할 것이다. 본 기관의 증례들은 시술 당시 모두 COVID-19 양성이었으나 의료진 감염은 0\%였다. 적절한 방호복 을 착용하고 조심스럽게 진행한다면, 각 환자에게 적절한 시 기에 기관절개술을 통한 환자의 호흡기 치료를 할 수 있을 것 이라 사료된다.

레벨D 방호복 후드 위에 헤드라이트를 착용하기 어려워 무 영등이 있는 곳에서 수술을 해야 한다거나, 수술 시야 옆에 불을 비춰주는 식으로 진행해야 하는 어려움이 있다는 ${ }^{20)}$ 보 고가 있으나 Fig. 1처럼 레벨 D보호복 후드의 환기시스템 연 결선을 잠시 분리한 후 헤드라이트를 착용하면 중환자실에 서도 좋은 시야를 확보할 수 있다. 실제로 중환자실 COVID-19 감염 환자는 전신상태가 좋지 않아 수술장으로 옮겨 전신마취를 시행하기 어려운 경우가 많고, 옮기는 과정에서 에어로졸을 통한 감염의 위험성이 있으며, 수술장 및 원내 감 염 확산 방지를 위해 본원에서는 15 증례 모두 음압 격리 중 환자실 내에서 기관 절개술을 시행하였다. 하지만 이 경우 수 술장에 비해 적절한 무균 상태 유지나 충분한 수술 기구의 준비가 어려운 경우가 많으며, 술자의 불편한 자세, 부적절한 조명, 환자의 움직임, 소란스러운 주변 환경 등의 영향으로 수술장에서의 시술보다 훨씬 어려운 점이 많다. ${ }^{21)}$ 경피적 확 장 기관 절개술의 경우 기구가 키트(kit)의 형태로 사용하기 편하게 구비되어 있으며, 짧은 시간 안에 쉽게 시행할 수 있는
장점이 있다. 하지만, 목이 짧거나 비만 환자, 목 신전(extension)이 잘되지 않은 환자에서 기관 천자의 위치를 가늠하기 어렵고, 출혈 등의 상황에서 수술 시야가 제한되는 단점이 있 으며 ${ }^{22)}$ 음압 격리 중환자실 내 기관 내시경 또는 굴곡형 내시 경을 볼 수 있는 이동식 모니터 등이 들어와야 하며, 사용 후 멸균 소독을 해야 하는 등의 번거로움도 있다. 또한, 기관지 내시경을 보면서 기관 내 삽관 튜브를 조금씩 빼면서 위치를 조정해야 하는 인력이 필요하고, 기관 내 삽관 튜브 내 기관내 시경을 삽입해서 시술을 진행하므로 기관 내 삽관 튜브를 통 한 COVID-19의 노출 위험성이 크다. 반면 hybrid MPDT는 기관내시경이 아닌 육안적으로 튜브의 위치를 확인하고 절개 공의 위치를 정할 수 있으며, 기관지내시경을 조작하는 인력 이 필요하지 않다. Takhar 등리에 따르면 전기소작기, 에너지 장비(ultrasonic or advanced bipolar based)의 사용 중 훔 발 생 및 이를 통한 바이러스 감염이 가능한데, hybrid MPDT는 $5 \mathrm{~mm}$ 크기의 작은 기관절개창을 cold knife를 사용하여 만 들고, 전기소작기를 사용하여 최소한의 지혈을 하므로, 기관 절개공을 통한 에어로졸 노출 위험이 적고, 절개창 크기가 작 으므로 인공호흡기 작동을 중단할 필요가 없다. 따라서 $\mathrm{CO}-$ VID-19 환자에게 기관절개술을 시행할 때, hybrid MPDT 를 사용한다면, 전통적 관혈적 기관절개술의 장점인 좋은 시 야를 확보한 상태에서, 변형된 경피적 확장 기관절개술을 통 해 기관내시경 없이 빠르고 간단하게 COVID-19 감염의 위 험성을 줄이면서, 시술에 필요한 최소 의료진으로 기관절개 술을 시행할 수 있을 것이다.

COVID-19 환자의 기관절개술의 최적 시기는 여전히 알 수 없으나 hybrid MPDT를 사용하여 적절한 시기에 시행한 다면 보다 안전한 COVID-19 치료를 할 수 있을 것이라 사 료된다.

\section{Acknowledgments}

This research was supported by Inha university research grant.

\section{Author Contribution}

Conceptualization: Ji Won Kim, Jung Soo Kim. Data curation: all authors. Formal analysis: Min Ji Kim, Ji Won Kim. Methodology: Min Ji Kim, Ji Won Kim, Yeon Soo Choi, Jin-Soo Lee. Project administration: Supervision: Ji Won Kim. Writing - original draft: Min Ji Kim. Writing_-review \& editing: Ji Won Kim.

\section{ORCIDs}

Ji Won Kim https://orcid.org/0000-0003-1587-9671

Min Ji Kim https://orcid.org/0000-0001-8422-2513

\section{REFERENCES}

1) Kim JK, Han DH. COVID-19 and smell loss. Korean J Otorhinolaryngol-Head Neck Surg 2020;63(11):491-6. 
2) Wi S, Suh GY. Treatment of critically ill patients with coronavirus disease 2019. Korean J Med 2021;96(1):22-9.

3) Bier-Laning C, Cramer JD, Roy S, Palmieri PA, Amin A, Añon JM, et al. Tracheostomy during the COVID-19 pandemic: Comparison of international perioperative care protocols and practices in 26 countries. Otolaryngol Head Neck Surg 2021;164(6):1136-47.

4) Chiesa-Estomba CM, Lechien JR, Calvo-Henríquez C, Fakhry N, Karkos PD, Peer S, et al. Systematic review of international guidelines for tracheostomy in COVID-19 patients. Oral Oncol 2020;108:104844.

5) Heyd CP, Desiato VM, Nguyen SA, O'Rourke AK, Clemmens CS, Awad MI, et al. Tracheostomy protocols during COVID-19 pandemic. Head Neck 2020;42(6):1297-302.

6) Kligerman MP, Vukkadala N, Tsang RKY, Sunwoo JB, Holsinger FC, Chan JYK, et al. Managing head and neck cancer patients with tracheostomy or laryngectomy during the COVID-19 pandemic. Head Neck 2020;42(6):1209-13.

7) Lamb CR, Desai NR, Angel L, Chaddha U, Sachdeva A, Sethi S, et al. Use of tracheostomy during the COVID-19 pandemic: American College of Chest Physicians/American Association for Bronchology and Interventional Pulmonology/Association of Interventional Pulmonology program directors expert panel report. Chest 2020; 158(4):1499-514.

8) McGrath BA, Brenner MJ, Warrillow SJ, Pandian V, Arora A, Cameron TS, et al. Tracheostomy in the COVID-19 era: Global and multidisciplinary guidance. Lancet Respir Med 2020;8(7):717-25.

9) Michetti CP, Burlew CC, Bulger EM, Davis KA, Spain DA. Performing tracheostomy during the Covid-19 pandemic: Guidance and recommendations from the Critical Care and Acute Care Surgery Committees of the American Association for the Surgery of Trauma. Trauma Surg Acute Care Open 2020;5(1):e000482.

10) Parker NP, Schiff BA, Fritz MA, Rapoport SK, Schild S, Altman $\mathrm{KW}$, et al. Tracheotomy recommendations during the COVID-19 pandemic. ScholarWorks [online] 2020 Mar [cited 2020 Mar 27]. Available from: URL: https://scholarworks.iupui.edu/bitstream/ handle/1805/23388/Parker2020Tracheostomy-recommendations. pdf? sequence $=1$.

11) Swain SK, Das S, Padhy RN. Performing tracheostomy in intensive care unit-A challenge during COVID-19 pandemic. Siriraj Med J 2020;72(5):436-42.

12) Vargas M, Russo G, Iacovazzo C, Servillo G. Modified percutaneous tracheostomy in COVID-19 critically ill patients. Head Neck
2020;42(7):1363-6.

13) Kim SK, Jung JH, Kim JS, Kim YK. Factors affecting wound healing after decannulation of tracheostomy tube. J Korean Acad Rehabil Med 2010;34(4):432-5.

14) Yang X, Yu Y, Xu J, Shu H, Xia J, Liu H, et al. Clinical course and outcomes of critically ill patients with SARS-CoV-2 pneumonia in Wuhan, China: A single-centered, retrospective, observational study. Lancet Respir Med 2020;8(5):475-81.

15) Kwak PE, Connors JR, Benedict PA, Timen MR, Wang B, Zhang Y, et al. Early outcomes from early tracheostomy for patients with COVID-19. JAMA Otolaryngol Head Neck Surg 2021;147(3):23944.

16) Angel L, Kon ZN, Chang SH, Rafeq S, Palasamudram Shekar S, Mitzman B, et al. Novel percutaneous tracheostomy for critically ill patients with COVID-19. Ann Thorac Surg 2020;110(3):1006-11.

17) Martin-Villares C, Perez Molina-Ramirez C, Bartolome-Benito M, Bernal-Sprekelsen M. Outcome of 1890 tracheostomies for critical COVID-19 patients: A national cohort study in Spain. Eur Arch Otorhinolaryngol 2021;278(5):1605-12.

18) Breik O, Nankivell P, Sharma N, Bangash MN, Dawson C, Idle M, et al. Safety and 30-day outcomes of tracheostomy for COVID-19: A prospective observational cohort study. Br J Anaesth 2020; 125(6):872-9.

19) Piazza C, Filauro M, Dikkers FG, Nouraei SAR, Sandu K, Sittel C, et al. Long-term intubation and high rate of tracheostomy in COVID-19 patients might determine an unprecedented increase of airway stenoses: A call to action from the European Laryngological Society. Eur Arch Otorhinolaryngol 2021;278(1):1-7.

20) Schuler PJ, Greve J, Hoffmann TK, Hahn J, Boehm F, Bock B, et al. Surgical tracheostomy in a cohort of COVID-19 patients. HNO 2021;69(4):303-11.

21) Shin HI, Jang KI, Kim KM, Nam IC. Comparison of surgical tracheostomy and percutaneous dilatational tracheostomy in intensive care unit patients. Korean J Otorhinolaryngol-Head Neck Surg 2019;62(5):288-93.

22) Cho YJ, Lim JH, Lee YJ, Nam IC. Severe complication of percutaneous dilatational tracheostomy. J Korean Soc Laryngol Phoniatr Logop 2016;27(1):54-7.

23) Takhar A, Walker A, Tricklebank S, Wyncoll D, Hart N, Jacob T, et al. Recommendation of a practical guideline for safe tracheostomy during the COVID-19 pandemic. Eur Arch Otorhinolaryngol 2020;277(8):2173-84. 